\title{
Ligamentum Flavum Cysts Causing Incapacitating Lumbar Spinal Stenosis
}

\author{
Salvatore DiMaio, Eric Marmor, Stephan Albrecht, Gérard Mohr
}

\begin{abstract}
Background: Cysts of the ligamentum flavum are rare and unusual causes of spinal compression. Methods: We report our experience of four cases of ligamentum flavum cysts occurring in the lumbar spine and discuss some of the possible etiologies and pathophysiologic mechanisms according to the available literature. Conclusion: This entity is clearly different from the synovial facetjoints or ganglion cysts.
\end{abstract}

RÉSUMÉ: Sténose spinale lombaire incapacitante causée par un kyste du ligament jaune. Introduction: Les kystes du ligament jaune sont rares et causent très rarement une compression spinale. Méthodes: Nous rapportons notre expérience au sujet de quatre cas de kystes du ligament jaune au niveau lombaire et nous discutons de l'étiologie et de la physiopathologie de cette entité à la lumière de la littérature actuelle. Conclusion: Cette pathologie est nettement différente des kystes synoviaux des articulations facettaires ou des kystes ganglionnaires.

Can. J. Neurol. Sci. 2005; 32: 237-242

Cysts of the ligamentum flavum are unusual causes of spinal compression. Their etiology and histopathologic classification have yet to be fully elucidated. We report our experience of four cases of ligamentum flavum cysts occurring in the lumbar spine and discuss some of the etiologies and possible pathophysiologic mechanisms for their development.

\section{CASe RePorts}

An outline of the cases is contained in the Table, and imaging examples are shown in Figure 1.

\section{Case 1}

The patient was an 82-year-old woman referred for recent onset of right-sided sciatica involving mostly the S1 distribution and causing major incapacitation because of severe pain. There was no pain on coughing; however, she had increased urinary frequency at night. On examination, motor function was normal and there was no sensory disturbance on examination of the legs. Reflexes were hypoactive in the right leg with plantar reflexes downgoing.

Computerized tomography (CT) imaging of the lumbo-sacral spine showed significant degenerative disease in the lumbar spine, as well as an epidural mass occupying the L5-S1 region, with a small posterocentral subligamentous hernia, possibly representing a synovial or arachnoid cyst but also compatible with a benign cystic tumour such as a schwannoma. Subsequent magnetic resonance imaging (MRI) demonstrated a voluminous epidural cystic lesion compressing the cauda equina to the right of the sac at L5-S1, compatible with a synovial cyst of the ligamentum flavum. In light of the acuity and degree of incapacitation of the disease, the patient was hospitalized for urgent laminectomy with microsurgical removal of the cyst.
The patient was placed under general endotracheal anaesthesia in knee-chest position. Longitudinal midline incision from L4 to S2 with exposure of the L5-S1 junction was performed as well as incision of the lumbosacral fascia and dissection of the paraspinal muscles. The lesion, thought to be originating from the right facet joint, was fragmented and extensively removed as well as the affected portion of ligamentum flavum.

Both the excised portion of ligamentum flavum and the cystic lesion were sent for pathological examination. The ligamentum flavum specimen consisted of an irregular fragment of beige, rubbery tissue measuring $2.2 \times 1 \times 0.6 \mathrm{~cm}$. It was composed largely of fibroadipose tissue and portions of dense, fibrocollagenous material. The cyst measured approximately $1.5 \mathrm{~cm}$ in greatest dimension, and the wall up to $0.3 \mathrm{~cm}$ in thickness. The lumen contained beige, friable, spongy material. Microscopically the specimen consisted of a pseudocyst, physically contiguous with a fragment of ligamentum flavum. The cyst wall was composed of dense fibrocollagenous tissue with a few areas of granulation tissue and chronic inflammation. There was no synovial lining. The lumen was filled with necrotic tissue, and in some areas the intraluminal material was viable with a distinct chondroid appearance. The lesion was, therefore, diagnosed as a nonsynovial cyst of the ligamentum flavum.

From the Divisions of Neurosurgery (SD, EM, GM) and Pathology (SA), Sir Mortimer B. Davis - Jewish General Hospital, McGill University, Montreal, QC, Canada. ReCEIVEd APRIL 23, 2004. ACCEPTED IN FINAL FORM November 30, 2004. Reprint requests to: Gérard Mohr, The Sir Mortimer B. Davis - Jewish General Hospital, 3755, Chemin de la Côte-Sainte-Catherine, Montreal, Quebec H3T 1E2 Canada. 
The postoperative course was uneventful and after 2.5 years of follow-up the patient continues to do very well, ambulating fully and her pain resolved.

\section{Case 2}

This 74-year-old male patient underwent placement of a ventriculoperitoneal shunt for normal pressure hydrocephalus eight months prior to his current presentation. He did relatively well with respect to cognitive function and had recuperated his walking ability. He remained, however, with some pain and during the recent weeks started complaining of major left-sided sciatica radiating into the L4 radicular territory. Sensory function was intact, as was motor function in the lower extremities although this was difficult to assess given the degree of pain. Reflexes were normal.

A CT scan of the spine showed multilevel degenerative changes with severe spinal stenosis at L3-L4 with a left lateralising soft tissue density lesion not seen in the previous scan, which was contributing to the stenosis. The MRI examination revealed a moderate to severe spinal stenosis at L3-L4 secondary to a prominent, posteriorly located synovial cyst with a moderate global disc bulge and facet osteoarthritis at this level.

The patient underwent laminectomy of L3-L4 with microsurgical removal of the epidural mass as described in Case 1. The extremely thick ligamentum flavum was gradually removed at L3-L4 and as expected from the MRI a voluminous cystic formation resulting from a diverticular extension of this synovial lining of the left facet joint was found and the content was sent to pathology, which confirmed the presence of normal synovial tissue as well as ligamentum flavum. Consequently this roundish cystic formation was gradually removed and the nerve roots completely decompressed.

The cyst specimen consisted of multiple fragments of pink, reddish, rubbery tissue measuring in aggregate $1.5 \times 1.5 \times 0.4 \mathrm{~cm}$. Histopathologic examination revealed ligamentum flavum with extensive neovascularisation and dystrophic calcifications with fragments of hyperplastic synovium, compatible with portions of a synovial cyst with some secondary degenerative or possibly reparative changes in the adjacent tissues.

The postoperative course was uneventful and satisfying, and by the two year follow-up the patient was doing very well.

\section{Case 3}

The third patient was a 76-year-old female with a one-week history of right-sided sciatica with progressive weakness in the right leg. She eventually became incapacitated in the right leg and presented to the emergency department. An urgent MRI was done, which revealed a posterior lesion causing significant compression of the L3-L4 thecal sac. The patient underwent partial bilateral L3 and L4 laminectomy with resection of the lesion on the same day.

Following laminectomy, a thickened ligamentum flavum could be seen as well as a right-sided cystic formation. The cyst and involved portion of ligamentum flavum were removed in total with complete decompression of the nerve roots and thecal sac.

The excised specimen consisted of multiple fragments of beige rubbery tissue measuring in aggregate $2 \times 2 \times 0.5 \mathrm{~cm}$. Histopathologic examination revealed fragments of ligamentum flavum with portions of eosinophilic, homogenous, necrotic debris probably representing necrotic ligamentum flavum. In viable segments intense neovascularization could be seen with proliferation of reactive fibroblasts. No synovium was seen.

The patient tolerated the procedure well and there were no complications postoperatively. She continues to do well after approximately one and a half years.

\section{Case 4}

This 57-year-old woman presented complaining of lower back pain with left-sided sciatica, having failed multiple conservative therapies and was completely debilitated on presentation, requiring admission for satisfactory pain control. An MRI was performed which demonstrated an extradural lesion that appeared to be cystic starting from the facet joint at the L5-S1 level. The patient electively underwent partial bilateral

\section{Table: Clinical, operative, radiological and pathological characteristics of patient series}

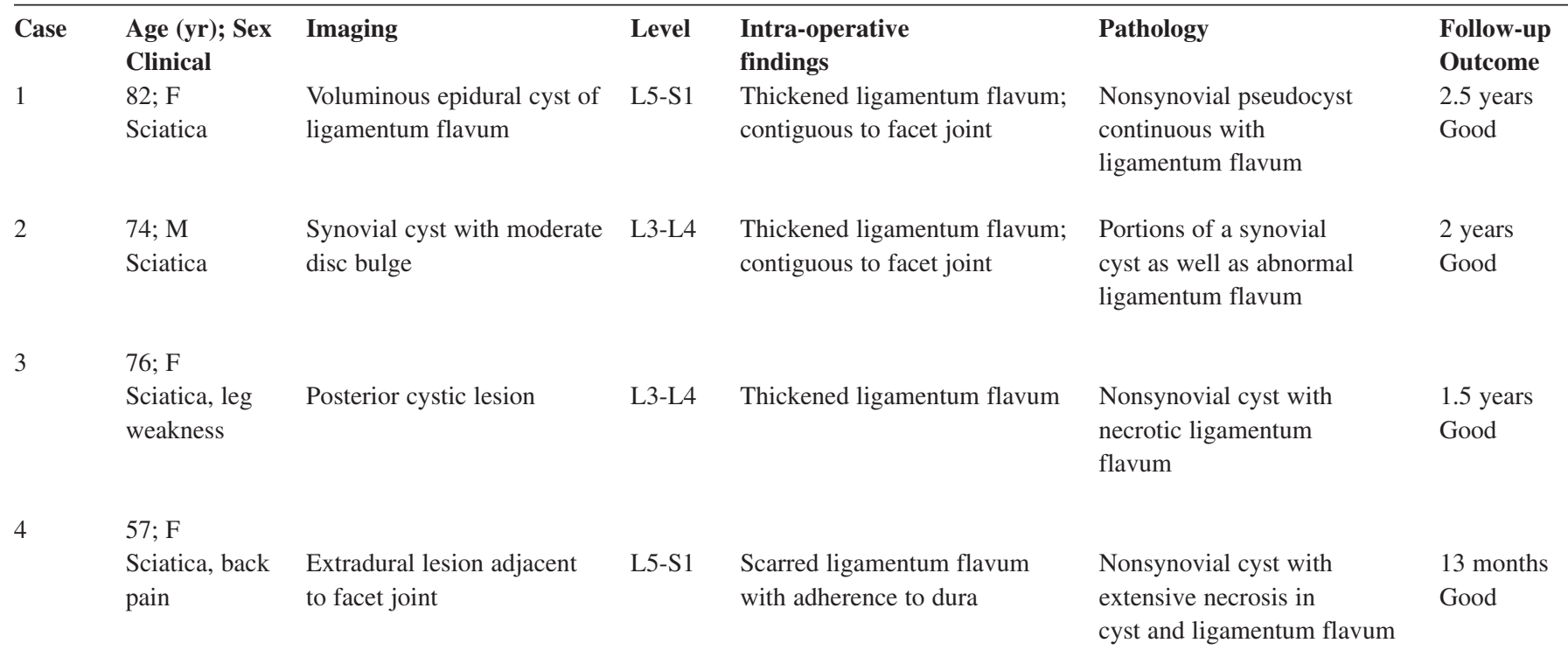



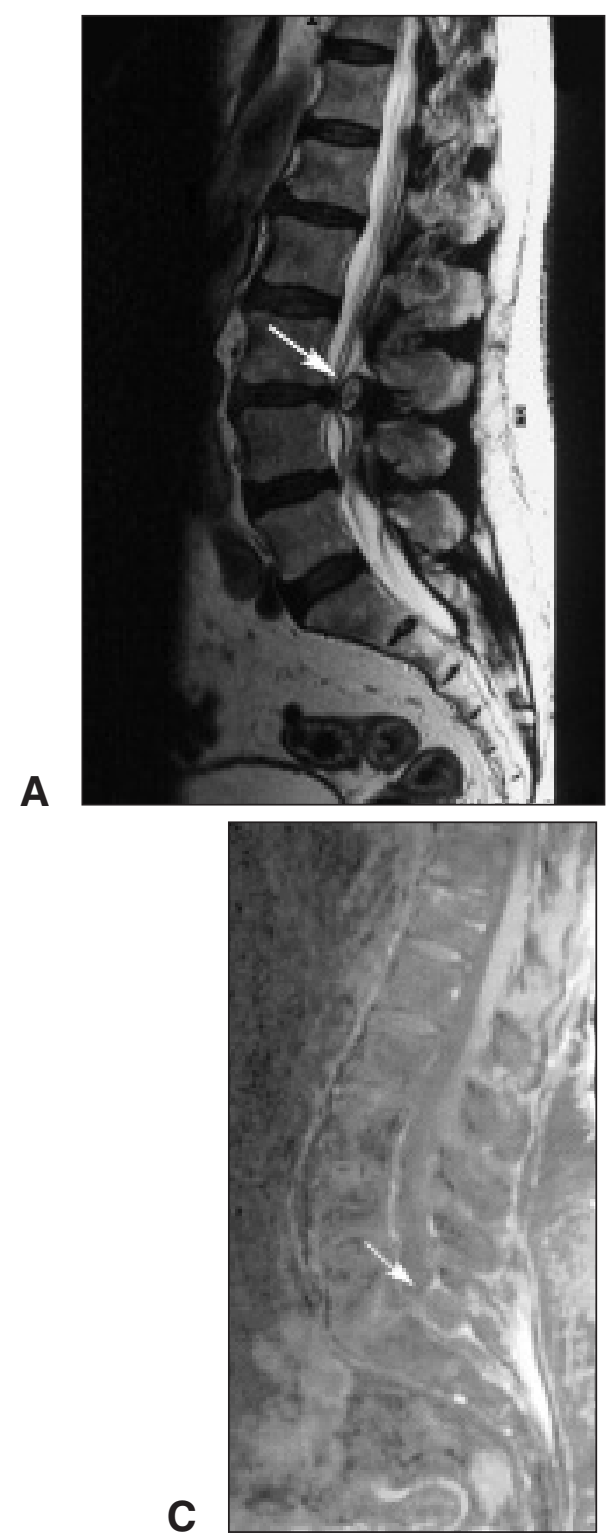
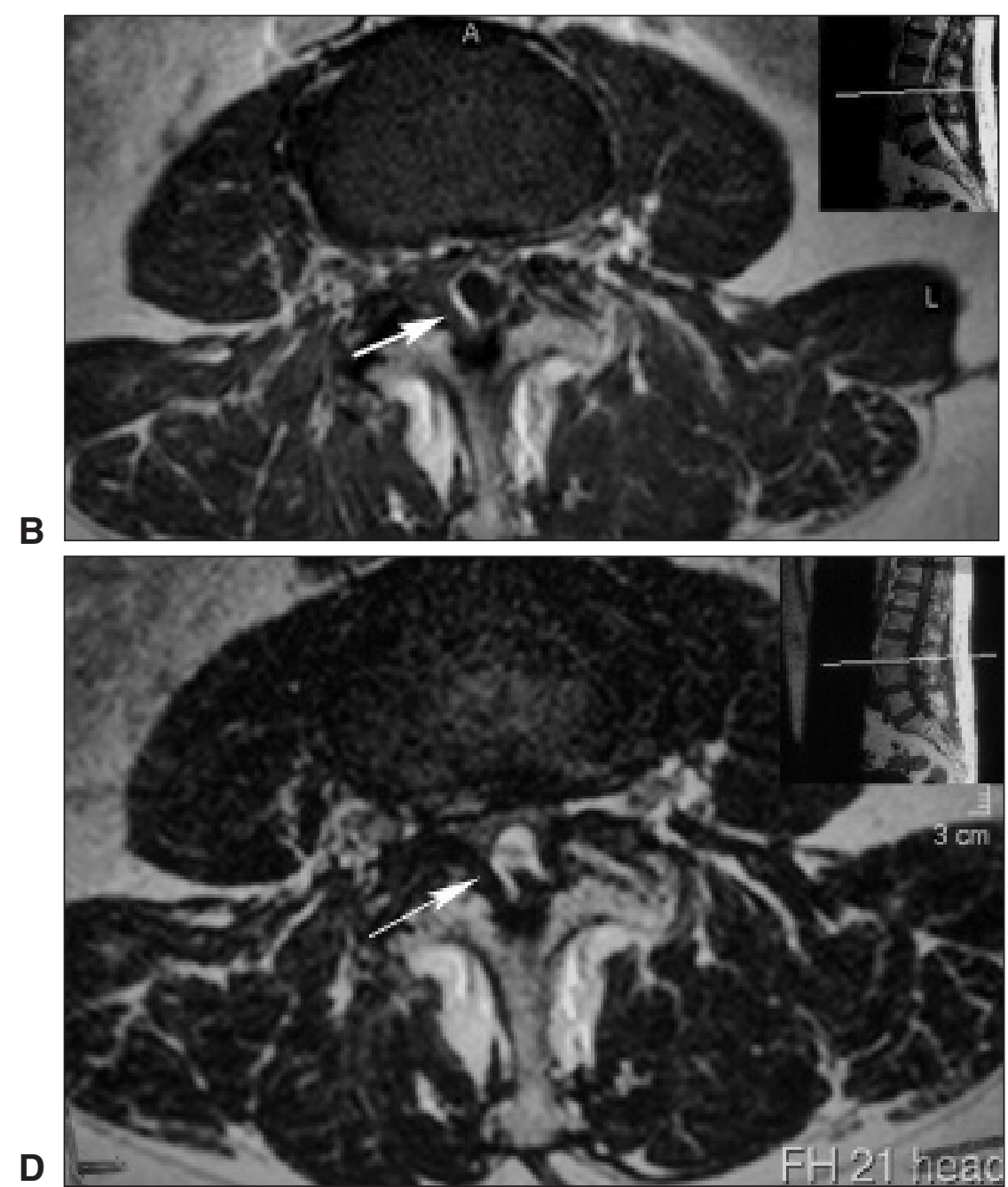

Figure 1: Magnetic resonance imaging appearance of ligamentum flavum cysts from our case series. T2 sagittal (A), T1 axial (B), T1 with gadolinium in sagittal section $(C)$, and $T 2$ axial $(D)$.

laminectomy at L5 and S1. Intraoperatively the ligamentum flavum was noted to be scarred and adherent to the dura. The extradural cystic lesion was eventually identified and was noted to cause significant compression of the thecal sac at the level of S1. The lesion was removed in its entirety as well as additional scar tissue from the nerve root with satisfactory decompression. Histopathological examination demonstrated areas of necrosis in both the ligamentum flavum and cartilage surrounded by intense granulation tissue with multinucleated giant cells. No definite synovial tissue was identified. In the postoperative course the patient did well and there were no complications. The patient continues to do extremely well after approximately 13 months follow-up.

\section{Discussion}

The term "juxta-facet" cyst was first implemented by Kao et $\mathrm{al}^{1}$ and Rhoton et $\mathrm{al}^{2}$ to describe cysts arising from the synovial joints of spinal facets, and encompasses both the synovial and ganglion sub-types commonly encountered in this area. Synovial cysts, characteristically, are continuous with the joint space and hence are lined by a pseudostratified columnar epithelium. They are filled with clear and serous fluid. Ganglion cysts have no such communication with the joint and do not possess a synovial cell lining. Their intraluminal contents are more gelatinous and viscous. ${ }^{3}$ Not all ligamentum flavum cysts can be described 
A
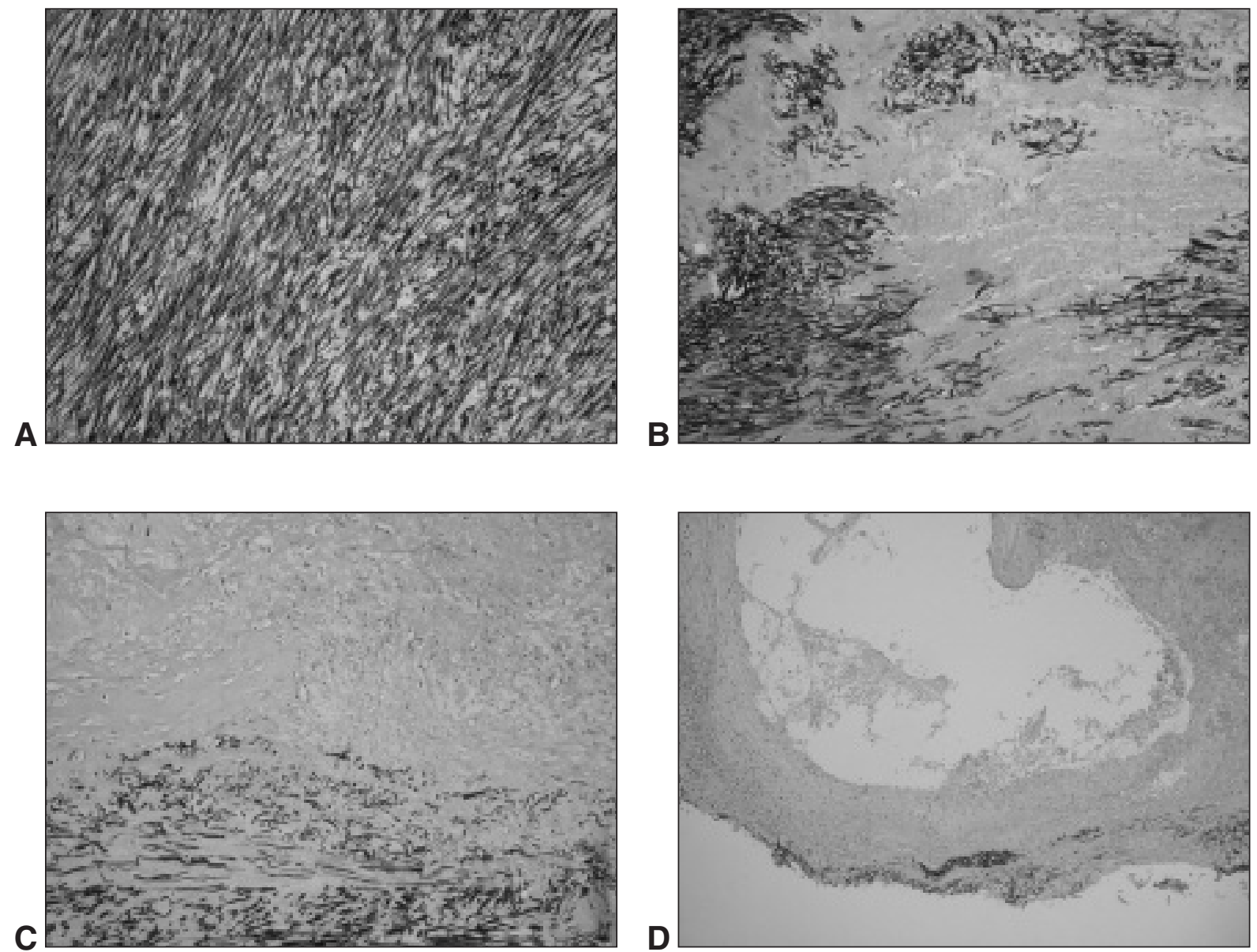

Figure 2: Histopathological sections from a sample patient in our series demonstrating ligamentum flavum (LF) and associated cystic degeneration. The sections were stained with the elastic van Giesan stain: elastic fibers are dark brown to black, while collagen stains red. Slide (A) shows a high power view of normal LF contained in the specimen. Slide (B) is a high-power view of an area of collagenous scarring in the $L F$ while slide $(C)$ reveals organising granulation tissue (upper two thirds of the image) replacing part of the LF. Slide (D) is a low power view demonstrating cystic degeneration of the LF.

solely as a synovial or ganglion sub-type based on pathological findings, ${ }^{4}$ however, nor are they all associated with spinal facets, hence suggesting that they represent unique lesions.

Contrary to juxta-facet cysts, there have been only a few cases of ligamentum flavum cysts described in the literature. ${ }^{3-15}$ The majority of published cases involved the lower lumbar spine, and corroborate the notion that ligamentum flavum cysts may be associated with microtrauma in the form of increased mobility at this level, ${ }^{16,17}$ with associated spinal degeneration. ${ }^{18}$ The majority of patient series in the literature regarding juxtafacet cysts demonstrate that facet joint degeneration is virtually always co-present, and the incidence of degenerative spondylolisthesis varies between 42 and $65 \% .{ }^{19}$ Hypertrophy of the ligamentum flavum, along with ligamentous degeneration and fibrosis, are also frequently present and likely to be sequelae of localized spinal trauma. ${ }^{20}$ Cyst formation may thus be part of a spectrum of more advanced ligamentous degeneration, which includes necrosis, fibrosis and calcification. ${ }^{5}$ In the present study, all four cases involved the lower lumbar spine, and histo- pathologic examination of the excised specimens (Figure 2) demonstrated evidence of degenerative changes within the ligamentum flavum, with scar remodelling and neovascularisation, supporting the theory that ligamentum flavum cysts occur within the context of longstanding deterioration ${ }^{13}$ at the implicated joint level.

Most ligamentum flavum cysts reported in the literature were also located laterally within the spinal canal. While possibly a consequence of chronic bony degenerative disease, this phenomenon may be further elucidated in certain cases by the observation that the yellow ligaments are not as thick laterally as they are medially.7 Furthermore, they form posterior recesses bilaterally to the vertebral bodies. These recesses are filled with epidural fat, ${ }^{21}$ offer an area of decreased resistance and may, as a result, tolerate cyst formation.

The distinction of ligamentum flavum cysts from intraspinal synovial and ganglion cysts has been suggested to be solely an exercise in nomenclature, ${ }^{22}$ in consideration of the high frequency of these lesions at the L4-L5 level, the coexistence of 
spinal degenerative disease, and overlapping histopathological features. In other case reports, these lesions are similarly classified together as juxta-facet cysts. ${ }^{5,6}$ While it is plausible that the etiologies of ligamentum flavum cysts described above are similar to those cysts implicating the spinal facet, the distinction is useful as surgical treatment of ligamentum flavum cysts does not require exploration of the facet joint. ${ }^{4}$ Various other pathologies involving the ligamentum flavum-distinct from the facet joint-have also been described in cases of spinal stenosis and compression, typically within the context of chronic degenerative changes or trauma at the implicated spinal level. These include other cystic lesions such as ligamentum flavum granulomas, ${ }^{23}$ as well as intraligamentous amyloid deposition, ${ }^{24}$ ossification of the ligamentum flavum, ${ }^{25}$ myxomatous degeneration of the lumbar ligamentum flavum, ${ }^{26}$ and ligamentum flavum hematoma. ${ }^{27}$

The CT appearance of juxta-facet cysts is often diagnostic and correlates well with pathologic findings. They typically consist of a cystic formation whose walls show calcification, and are located adjacent to facet joints that frequently show signs of degeneration. ${ }^{28}$ Ligamentum flavum cysts, conversely, have not been observed to cause rim calcification. ${ }^{29}$ On MRI (Figure 1), juxta-facet cysts appear as well-delineated cystic masses; the rim of synovial cysts are typically isointense to slightly hyperintense compared to cerebrospinal fluid in $\mathrm{T} 1,{ }^{30}$ and hypointense in $\mathrm{T} 2$. The rim contents have variable intensities and several classifications have been proposed. ${ }^{19}$ In the case of ligamentum flavum cysts, they are seen adjacent to the ligamentum flavum ${ }^{10}$ and there is no observable communication with the spinal facet joint. When intraluminal hemorrhage occurs in a minority of cases, they are easier to distinguish from herniated disk fragments and most neoplasms. ${ }^{4}$ In addition to other cystic lesions that may affect the lumbar spine, calcium pyrophosphate dihydrate deposits have been observed in the ligamentum flavum among patients presenting with lumbar pain and/or radiculopathy, and typically are hypointense on MRI and show calcifications on CT imaging. ${ }^{31}$ They have also been noted to occur in conjunction with synovial cysts of the lumbar spine. ${ }^{32}$

The majority of symptomatic juxta-facet cysts usually present with radiculopathy, such as sciatica in the case of lumbar cysts, and can mimic symptoms related to intervertebral disk herniation. ${ }^{33}$ The progression can be both acute and sub-acute. Not all juxta-facet cysts are symptomatic, and can be discovered incidentally. ${ }^{34}$ In the four cases described, however, the juxtafacet cysts were the source of incapacitating pain.

Most conservative therapies are temporary and have varying success in the short term. Percutaneous steroid injection of facet and juxta-facet synovial cysts has achieved variable but generally good short-term outcomes. ${ }^{35,36}$ Evidence-based information on the surgical management of ligamentum flavum cysts is limited. The goal of surgery in juxta-facet cysts is spinal decompression via laminectomy and resection of the cyst and affected ligamentum flavum. Complete excision at the base of the ligamentous insertion of the cyst assures a minimal rate of recurrence. ${ }^{37}$ While nearly $95 \%$ of all operated synovial cysts can be removed in their entirety, ${ }^{38,39}$ a major reported intraoperative difficulty lies in the presence of adhesions to the dural wall, which is the main causative factor of incomplete resections. Literature series regarding synovial cysts have reported excellent levels of recuperation of neurologic function in $87-98 \%$ of cases. ${ }^{40,41}$ Likewise, improvement in both pain and neurologic function in the majority of patients with both ligamentum flavum and juxta-facet cysts has been reported. ${ }^{42}$ In our present series, surgical removal of the cyst and affected ligamentum flavum resulted in marked improvement of pain and reversal of neurologic symptoms in all four patients.

In conclusion, ligamentum flavum cysts represent a rare cause of lumbar spinal stenosis. Several features of these lesions suggest that they represent entities distinct from classical juxtafacet cysts. We have presented four cases from our own experience, and discussed their imaging features as well as possible mechanisms for their development.

\section{REFERENCES}

1. Kao CC, Winkler SS, Turner JH. Synovial cyst of spinal facet: case report. J Neurosurg 1974; 41: 372-376.

2. Rhoton AL, Kao CC, Uihlein A. Extradural ganglion cyst. In: Vinken PJ, Bruyn GW (Eds). Handbook of Clinical Neurology. North-Holland Pub Co., Amsterdam: North Holland, 1976: 605609.

3. Yamamoto A, Nishiura I, Handa H, Kondo A. Ganglion cyst in the ligamentum flavum of the cervical spine causing myelopathy: report of two cases. Surg Neurol 2001; 56: 390-395.

4. Mahallati H, Wallace CJ, Hunter M, Bilbao JM, Clark AW. MR imaging of a hemorrhagic and granulomatous cyst of the ligamentum flavum with pathologic correlation. Am J Neuroradiol 1999; 20: 1166-1168.

5. Abdullah AF, Chambers RW, Daut DP. Lumbar nerve root compression by synovial cysts of the ligamentum flavum: report of four cases. J Neurosurg 1984; 60: 617-620.

6. Kjerulf TD, Terry DW, Boubelik RJ. Lumbar synovial or ganglion cysts. Neurosurgery 1986; 19: 415-420.

7. Moiel RH, Ehni G, Anderson MS. Nodule of the ligamentum flavum as a cause of nerve root compression. J Neurosurg 1967; 27: 456-458.

8. Bärlocher C, Seiler RW. Vertebral erosion and a ligamemtum flavum cyst: case illustration. J Neurosurg: Spine 2000; 93: 335

9. Haase J. Extradural cyst of ligamentum flavum. Acta Orthop Scand 1972; 43: 32-38

10. Terada H, Yokoyama Y, Kamata N, Hozumi T, Kondo T. Cyst of the ligamentum flavum. Neuroradiology 2001; 43: 49-51.

11. Baker JK, Hanson GW. Cyst of the ligamentum flavum. Spine 1994; 19: 1092-1094.

12. Vernet O, Fankhauser H, Schnyder P, Déruaz J-P. Cyst of the ligamentum flavum: report of six cases. Neurosurgery 1991; 29: 277-283.

13. Hatem O, Bedou G, Négre C, Bertrand JL, Camo J. Intraspinal cervical degenerative cyst: report of three cases. J Neurosurg Spine 2001 Jul;95(1): 139-142.

14. Chan LF, Lui CC, Cheng MH, Lin JW. Ganglion cyst in the ligamentum flavum of the cervicothoracic junction. J Formos Med Assoc 1996; 95: 490-492.

15. Azzam CJ. Midline lumbar ganglion/synovial cyst mimicking an epidural tumor: case report and review of pathogenesis. Neurosurgery 1988; 23: 232-234.

16. Sabo RA, Tracy PT, Weinger JM. A series of 60 juxtafacet cysts: clinical presentation, the role of spinal instability, and treatment. J Neurosurg 1996; 85: 560-565.

17. Kao CC, Uihlein A, Bickel WH, Soule EH. Lumbar intraspinal extradural ganglion cyst. J Neurosurg 1968; 29: 168-172.

18. Beamer YB, Garner JT, Shelden CH. Hypertrophied ligamentum flavum. Clinical and surgical significance. Arch Surg 1973; 106: 289-292.

19. Apostolaki E, Davies EM, Evans N, Cassar-Pullicino VN. MR imaging of lumbar facet joint synovial cysts. Eur Radiol 2000; 10: 615-623.

20. Dockerty MB, Love JG. Thickening and fibrosis (so-called 
hypertrophy) of the ligamentum flavum: a pathologic study of 50 cases. Mayo Clin Proc 1940; 15: 161-166.

21. Harrison GR. Topographical anatomy of the lumbar epidural region: an in vivo study using computerized axial tomography. $\mathrm{Br} \mathrm{J}$ Anaesth 1999; 83: 229-234.

22. Savitz MH, Sachdev VP. Cyst of the ligamentum flavum: report of six cases [comment]. Neurosurgery 1992; 30: 461-462.

23. Bilbao JM, Horsey W, Gonsalves C, Chalvardjian A. Compression of the cauda equina due to a necrobiotic granuloma of ligamentum flavum. Can J Neurol Sci 1975; 2: 135-138.

24. Gagne F. Depots amyloides intraligamentaires dans la stenose du canal rachidien. Can J Neurol Sci 1995; 22: 164-167.

25. Kruse JJ, Awasthi D, Harris M, Waguespack A. Ossification of the ligamentum flavum as a cause of myelopathy in North America: report of three cases. J Spinal Disord 2000; 13: 22-25.

26. Yoshii S, Ikeda K, Murakami H. Myxomatous degeneration of the ligamentum flavum of the lumbar spine. Spinal Cord 2001; 39: 488-491.

27. Yuceer N, Baskaya MK, Smith P, Willis BK. Hematoma of the ligamentum flavum in the lumbar spine: case report. Surg Neurol 2000; 53: 598-600.

28. Hemminghytt S, Daniels DL, Williams AL, Haughton VM. Intraspinal synovial cysts: natural history and diagnosis by CT. Radiology 1982; 145: 375-376.

29. Bloch J, Hawelski S, Benini A. Cyst of the ligamentum flavum of the lumbar spine: description of 6 cases. Schweiz Med Wochenschr 1997; 26: 728-732.

30. Jackson DAJ, Atlas SW, Mani JR, Norman D. Intraspinal synovial cysts: MR imaging. Radiology 1989; 170: 527-530.

31. Muthukumar N, Karuppaswamy U. Tumoral calcium pyrophosphate dihydrate deposition disease of the ligamentum flavum. Neurosurgery 2003; 53: 103-109.

32. Gadgil AA, Eisenstein SM, Darby A, Pullicino C. Bilateral symptomatic synovial cysts of the lumbar spine caused by calcium pyrophosphate deposition disease: a case report. Spine 2002; 27: E428-E431.

33. Freidberg SR, Fellows T, Thomas CB, Mancall AC. Experience with symptomatic spinal epidural cysts. Neurosurgery 1994; 34: 989993.

34. Hsu KY, Zucherman JF, Shea WJ, Jeffrey RA. Lumbar intraspinal synovial and ganglion cysts (facet cysts): ten-year experience in evaluation and treatment. Spine 1995; 20: 80-89.

35. Bureau NJ, Kaplan PA, Dussault RG. Lumbar facet joint synovial cyst: percutaneous treatment with steroid injections and distention--clinical and imaging follow-up in 12 patients. Radiology 2001; 221: 179-185.

36. Lim AK, Higgins SJ, Saifuddin A, Lehovsky J. Symptomatic lumbar synovial cyst: management with direct CT-guided puncture and steroid injection. Clin Radiol 2001; 56: 990-993.

37. Baba H, Furusawa N, Maezawa Y, et al. Ganglion cyst of the posterior longitudinal ligament causing lumbar radiculopathy: case report. Spinal Cord 1997; 35: 632-635.

38. Howington JU, Connolly ES, Voorhies RM. Intraspinal synovial cysts: 10-year experience at the Ochsner Clinic. J Neurosurg Spine 1995; 91: 193-199.

39. Lyons MK, Atkinson JL, Wharen RE, et al. Surgical evaluation and management of lumbar synovial cysts: the Mayo Clinic experience. J Neurosurg Spine 2000; 93: 53-57.

40. Métellus P, Flores-Parra I, Fuentes S, et al. Kystes synoviaux lombaires: aspects cliniques et prise en charge chirurgicale; étude rétrospective de 32 cas. Neurochirurgie 2003; 49: 73-82.

41. Ben Salem D, Sauvage PJ, Pellerin O, Krausé D, Ricolfi F. Prise en charge thérapeutique des kystes synoviaux lombaires: à propos de l'article de P. Métellus et al. Neurochirurgie 2003; 49: 616-617.

42. Banning CS, Thorell WE, Leibrock LG. Patient outcome after resection of lumbar juxtafacet cysts. Spine 2001; 26: 969-972. 